\title{
Implementation of Android-Based AIS and MMG Model for Safety Analysis of Small Coastal Fishing Vessel
}

\author{
I Putu Sindhu Asmara ${ }^{1, a, *}$, Adianto ${ }^{2, b}$, Sarah Putri Pratiwi ${ }^{3}$, Nurul Istiqomah ${ }^{3}$, Arum \\ Mujayanah ${ }^{3}$ \\ ${ }^{1}$ Department of Shipbuilding Engineering, Politeknik Perkapalan Negeri Surabaya, PUI \\ Keselamatan Kapal dan Instalasi Laut, PUT Kapal-Kapal Kecil Surabaya, Indonesia \\ ${ }^{2}$ Department of Marine Electrical Engineering, Politeknik Perkapalan Negeri Surabaya, PUI \\ Keselamatan Kapal dan Instalasi Laut, PUT Kapal-Kapal Kecil, Surabaya, Indonesia \\ ${ }^{3}$ Department of Shipbuilding Engineering, Politeknik Perkapalan Negeri Surabaya, Surabaya, \\ Indonesia \\ a.ptsindhu@gmail.comb.adiantoanditsan@gmail.com \\ *corresponding author
}

Keywords: Android-Based AIS, emergency level, environment stress, MMG model, small coastal fishing vessel.

Abstract: This paper introduces the trial on the development of the Android-based Automatic Identification System (AIS) on small-scale traditional fishing boats. Information and communication system between the small vessel and land-based center is developed using Android system. The AIS data including the position, course over ground, speed over ground and heading of vessels is transmitted by the shipboard package and received by the data center. The system is designed to be able to send a message to the vessels. In this case, command of stopping maneuver is transmitted to the shipboard package. The data obtained from the system is used as the validation of the vessels maneuverability simulated by using Mathematical Maneuvering Group (MMG) model. The deviation is analyzed and parameters of MMG model are evaluated. The safety indices of the vessel in the research area in terms of Environment Stress and Emergency Level are calculated based on the distances to obstacles.

\section{Introduction}

Monitoring and surveillance of the fishing vessel, especially for the small coastal fishing vessel having the capacity of less than 30 gross tonnages (GT) has been a big challenge in Indonesia. On the contrary, the Vessel Monitoring System (VMS) for fishing vessels of more than 30 GT not only have been completely established but also have already been transparent by combining the VMS data with data of a worldwide Automatic Identification System (AIS) [1]. The Law of Government of Republic Indonesia number 23 of 2014 about local government has been implemented since 2017. The small-scale fisheries with the vessel of less than 5 GT are empowered by local district government but the coast area of 0 to 12 miles from the shoreline is managed by local province government.

Several problems have arisen due to the absence of the coastal vessel monitoring system and the implementation of the law, such as: the accident of collision with general cargo ship in a voyaging 
lane due to undetected by the safety system equipment and unseen by Officer on Watch, and detention of fisherman due to breaking the border of the provincial water. The satellite-based VMS implemented by the Ministry of Marine Affair and Fisheries of Indonesia is expensive for traditional fisheries having the vessel of less than 5 GT. The provincial and district government should take innovation and coordination on the monitoring and surveillance of the small-scale fishing vessel. The goal of this study is to establish AIS data for monitoring system (AIS-VMS) of the coastal fishing vessel. The system is implemented at a coastal fishing area near to the Port of Tanjung Perak, Surabaya, as shown in Fig. 1. The AIS-VMS application packages are tested on 3 (three) vessels with the capacity of 1 Gross Tonnage (GT). The objectives are:

1. to trial the system and evaluate the quality of the AIS data,

2. to provide the usage of the data on the analysis of maneuverability, and

3. to assess safety index of the vessel in the research area.

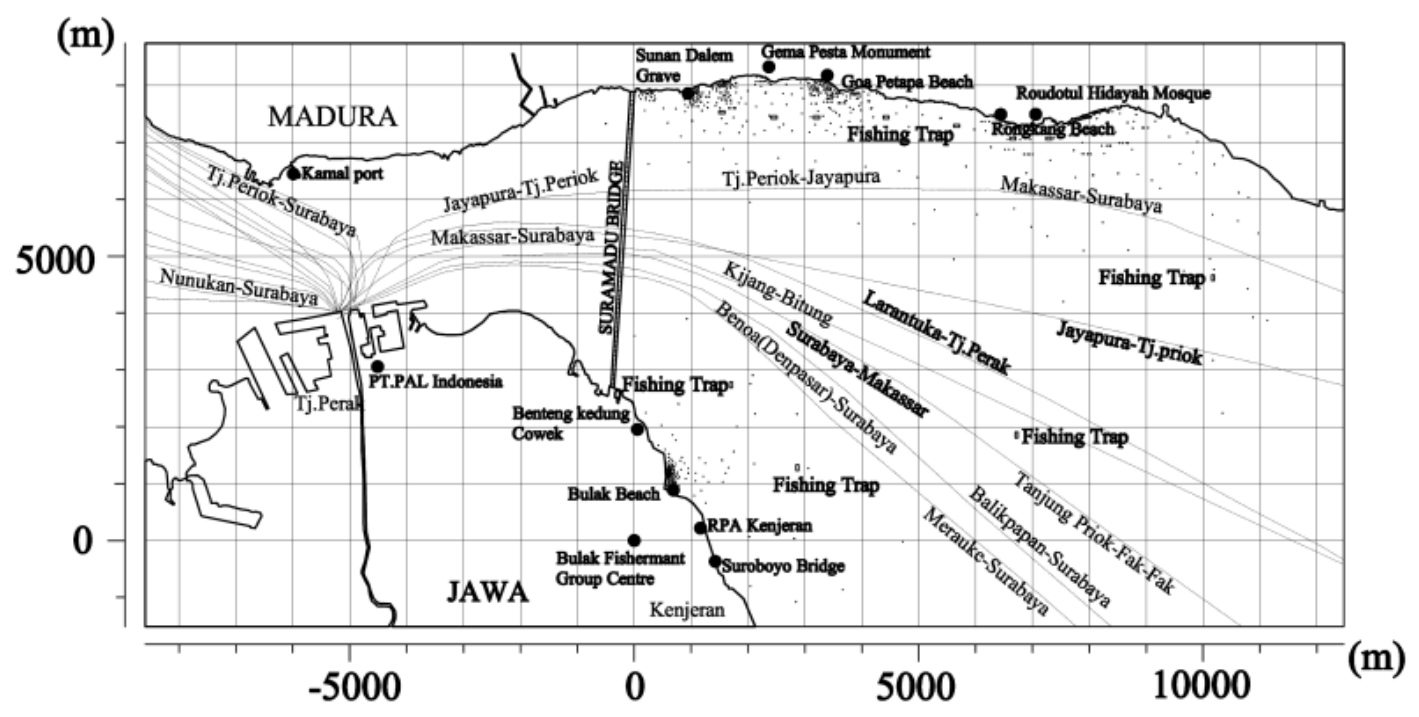

Figure 1: Area of study

The AIS data have been utilized on the analysis of traffic safety [2] in the Gulf of Finland. The usage of AIS data has also been implemented in Madura Strait on some issues to improve ship safety operation [3]. However, AIS data in Indonesia has not yet covered the fishing vessels with the capacity of less than 30 GT. Estimation of collision risk using AIS data and MMG modle has been introduced by the author [4]. In this paper, a system to derive AIS data on the small coastal fishing vessels is implemented and the usage of the data on the evaluation of maneuverability and the assesment of safety is introduced.

\section{Methodology}

The flow of this study is shown in Fig. 2. The system is implemented on three fishing boats. The AIS data consists of longitude and latitude positions as well as the heading is plotted on a map. The stopping maneuverability of the fishing boats is determined based on the AIS trajectories. The stopping distance of the boats is calculated in the MMG model and compared to the AIS data. The hull, propeller and rudder coefficients of MMG model for the small coastal fishing vessel is evaluated and validated based on the AIS trajectories. The coordinate system of MMG model is shown in Fig. 3. 


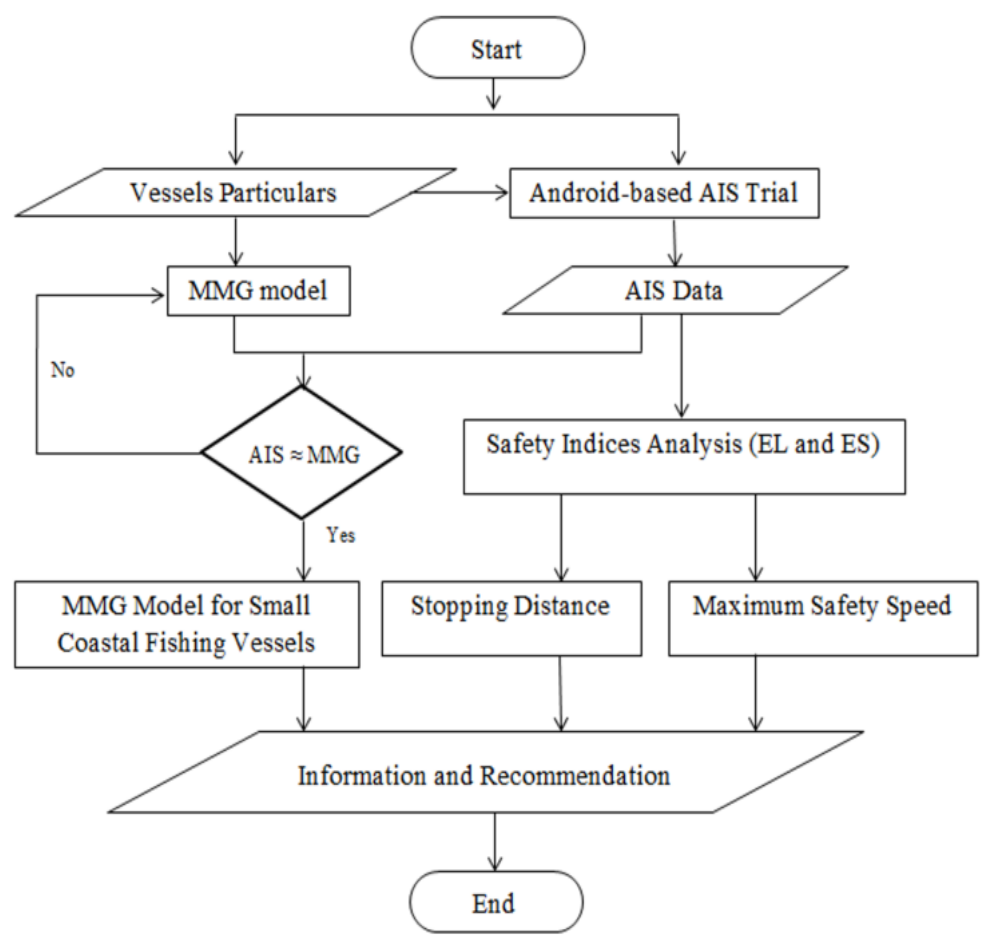

Figure 2: The flow of study

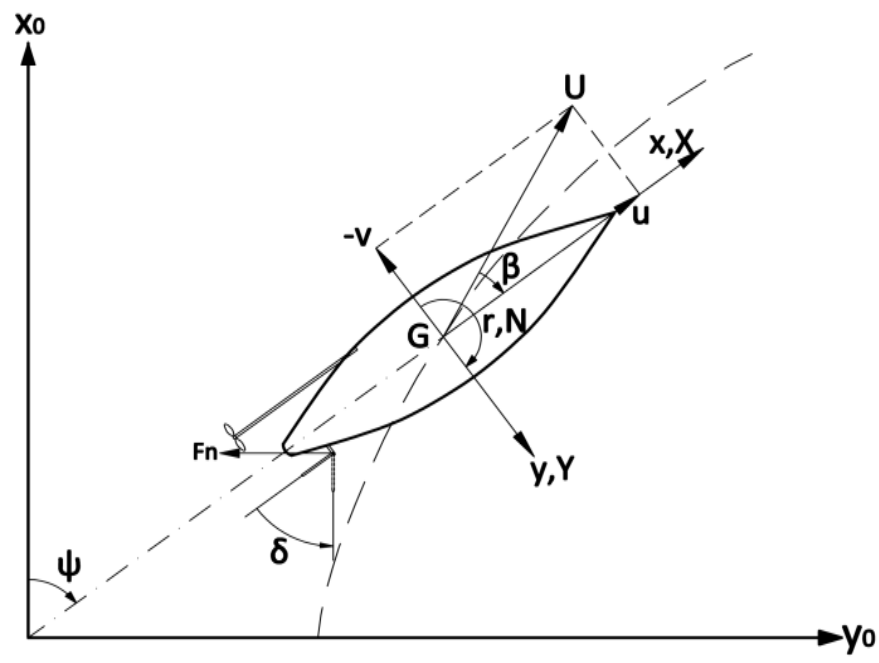

Figure 3: Coordinate system of MMG model

The MMG model consists of three motion including surging, swaying and yawing motions as expressed in (1) to (3) $[5,6]$. The effects of wind on ship maneuvering are calculated in the MMG model based on Fujiwara's estimation of wind forces and moment [7]. The current effect is calculated on the relative velocity with respect to the moving frame.

The trajectories of vessels derived from the Android-based AIS data are compared to the trajectories esimated by the MMG model using derivatif coefficients published by Yoshmura et. al $[5,6]$. In addition, the Emergency Level and Environment Stress indices of the boat in the research area are calculated.

$$
\text { Surge: }\left(m+m_{x}\right) \dot{u}_{G}-\left(m+m_{y}\right) v_{G} r_{G}=X_{H}+X_{P}+X_{R}+X_{W}
$$




$$
\begin{array}{r}
\text { Sway: }\left(m+m_{y}\right) \dot{v}_{G}+\left(m+m_{y}\right) u_{G} r_{G}=Y_{H}+Y_{P}+Y_{R}+Y_{W} \\
\text { Yaw: }\left(I_{Z Z}+J_{z z}\right) \dot{r}_{G}=\left(N_{H}+N_{P}+N_{R}+N_{W}\right)-X_{G}\left(Y_{H}+Y_{P}+Y_{R}+Y_{W}\right)
\end{array}
$$

The EL is analyzed based on the scenario of the small coastal fishing vessel is in a crossing position with a vessel on a voyaging lane. The ES is calculated to assess the difficulty of the ship in the voyaging lane due to any obstacles located in the area. The EL method is presented by (4) as follows [8]:

$$
E L=1-T T C / S S T
$$

where:

TTC $=$ the Time to Collision

SST $=$ the Shortest Stopping Time

The ES method calculated using (5). Subjective judgments based on topographical obstacles (SJL) and traffic obstacles (SJS) are analyzed according to the equations proposed by Inoue et al [9].

where:

$$
E S=\sum_{j} S J_{L j}+\sum_{j} S J_{S j}
$$

$\mathrm{j}=$ the ship course over ground $(\mathrm{COG})$, from $\mathrm{COG}-90 \mathrm{o}$ to $\mathrm{COG}+90 \mathrm{o}$.

\section{Results}

There is six traditional fisherman group in the research area, five group located in the coast of Madura Island and a group in the Coast of Jawa Island. The number of small fishing vessels in the research area is about 200 vessels per group.

\subsection{Android-based AIS Stopping Trajectories and Emergency Level}

The main dimension of the vessels used for the implementation of the system is presented in Table 1. The lines plan of a vessel is shown in Fig 4. The AIS data of the vessels recorded by the system are plotted and the trajectories are presented in Figs. 5 and 6 . The path of the vessels presented in Fig. 5 aren't smooth indicating AIS data is less accurate. The vessel position of longitude or latitude changes in every 3 to 5 minutes. The stopping distance of the vessels is shown in Fig. 6.

Table 1: Main Dimensions of 1 GT Fishing Vessels

\begin{tabular}{|l|r|r|r|}
\hline \multicolumn{1}{|c|}{ Dimensions } & \multicolumn{1}{c|}{ Vessel 1 } & Vessel 2 & \multicolumn{1}{c|}{ Vessel 3 } \\
\hline LOA, meter $(\mathrm{m})$ & 8.41 & 8.11 & 8.37 \\
\hline LPP, meter $(\mathrm{m})$ & 7.98 & 7.62 & 7.82 \\
\hline $\mathrm{B}, \quad$ meter $(\mathrm{m})$ & 2.04 & 1.91 & 2.08 \\
\hline $\mathrm{H}, \quad$ meter $(\mathrm{m})$ & 0.80 & 0.65 & 0.88 \\
\hline $\mathrm{T}, \quad$ meter $(\mathrm{m})$ & 0.50 & 0.37 & 0.47 \\
\hline $\mathrm{C}_{\mathrm{B}}$ & 0.394 & 0.386 & 0.420 \\
\hline Engine, BHP/RPM & $5.5 / 2200$ & $6.5 / 2200$ & $9.5 / 3600$ \\
\hline Propeller diameter $(\mathrm{m})$ & 0.24 & 0.20 & 0.24 \\
\hline Rudder Area $\left(\mathrm{m}^{2}\right)$ & 0.246 & 0.232 & 0.225 \\
\hline
\end{tabular}




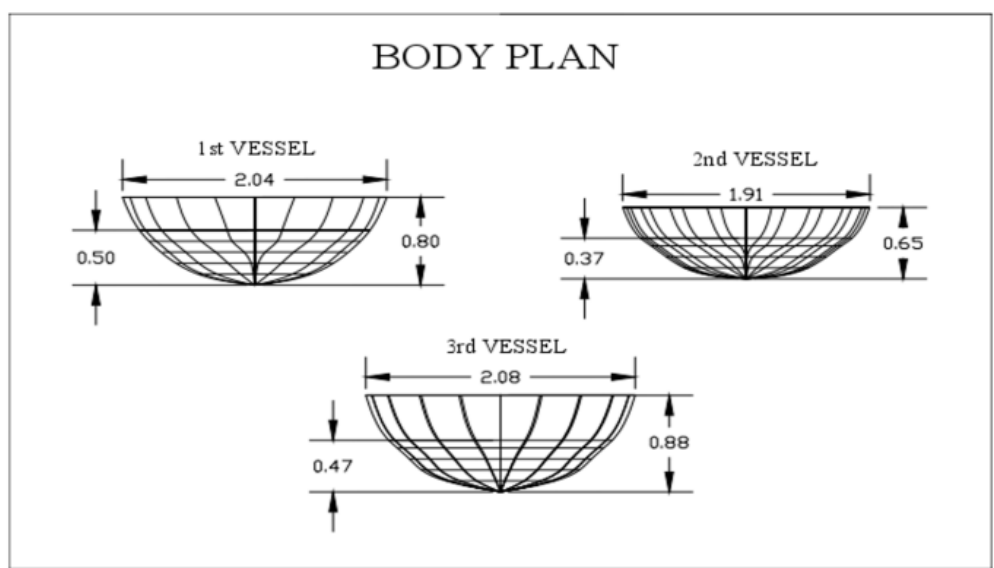

Figure. 4: Lines Plan

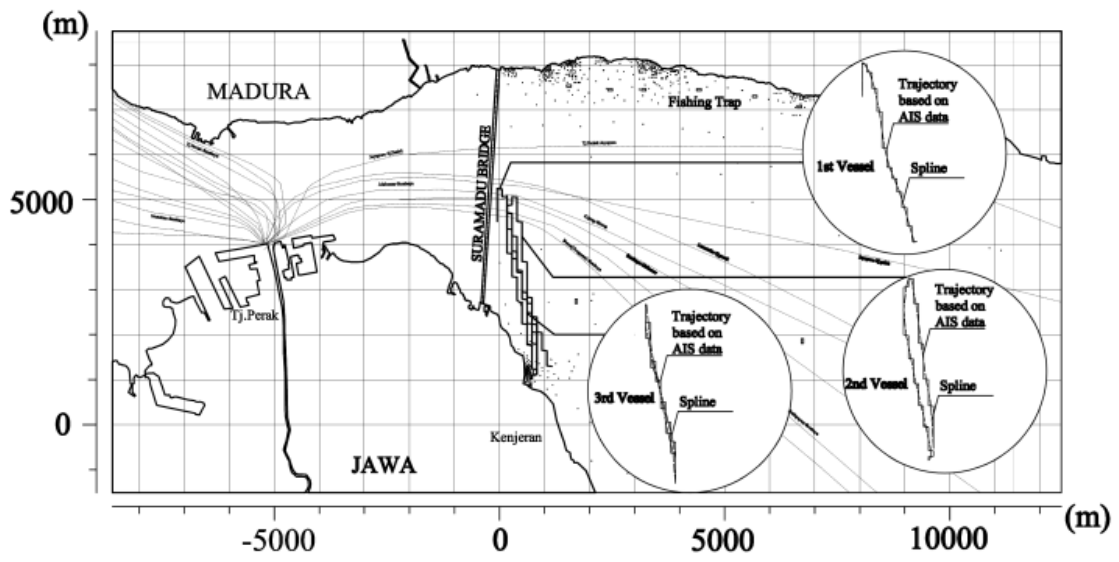

Figure 5: Trajectories of fishing vessels based on AIS data

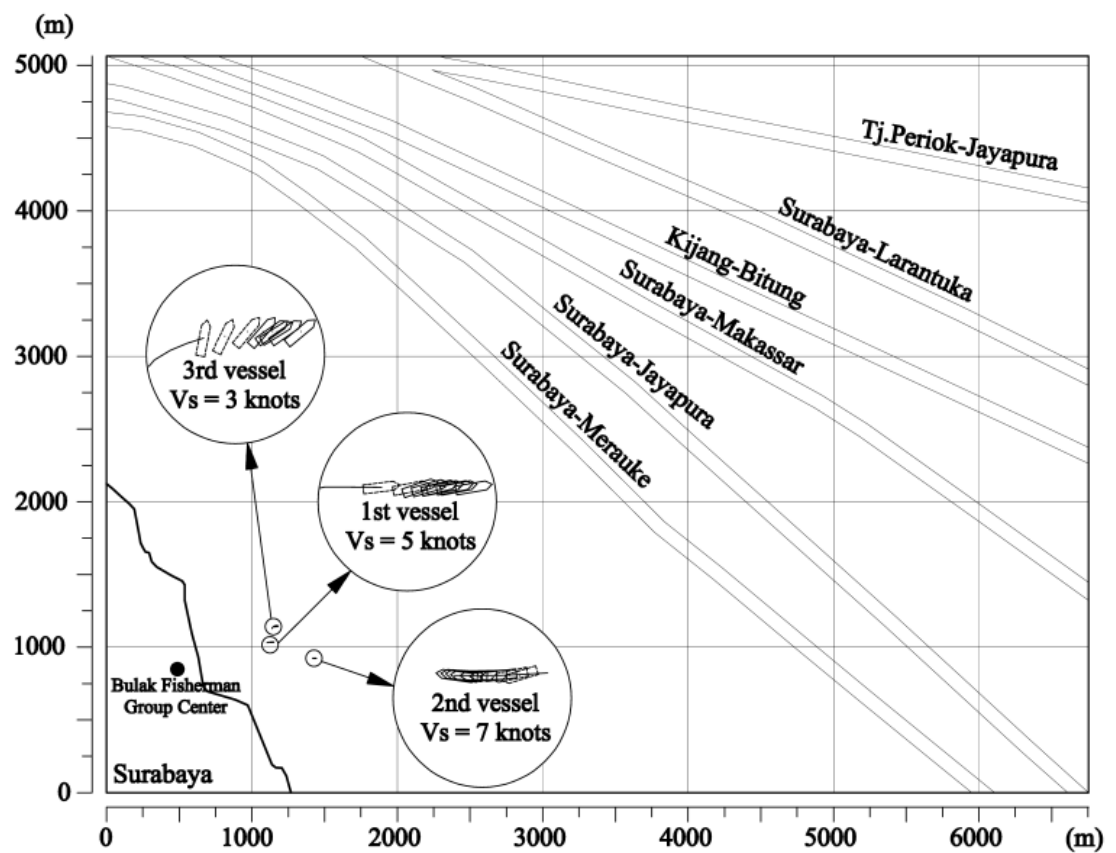

Figure 6: Stopping trajectories based on AIS data 
Table 2: Stopping Maneuverability of 1 GT Fishing Vessels

\begin{tabular}{|l|c|}
\hline \multicolumn{1}{|c|}{ Maneuverability } & 1 GT Coastal Fishing Vessel \\
\hline Average Stopping distance, meter (m) & 11.58 \\
\hline Average Stopping Time, second (s) & 55 \\
\hline Average Emergency Level Value & $\begin{array}{c}0.6749 \\
\text { (unsafe) }\end{array}$ \\
\hline Acceptance Maximum Speed, (knots) & 1,9 \\
\hline
\end{tabular}

The current speed is 0.74 to the East and the wind speed is 7 knots from the West. Based on the trajectories, the ability of stopping maneuver is identified and presented in Table 2. The fisherman usually shut down the engine at the distance of 10 meters from an obstacle. The stopping maneuver will be safe at the obstacle distance of $10 \mathrm{~m}$ if the maximum initial speed is 1,9 knots.

\subsection{MMG-based Stopping Trajectories.}

Simulation of stopping maneuver is developed using MMG model. The characteristic of the propeller is adapted from an open water propeller characteristic [10] as shown in Fig. 7. The stopping distance predicted by using MMG model is 36 meters as shown in Fig. 8.

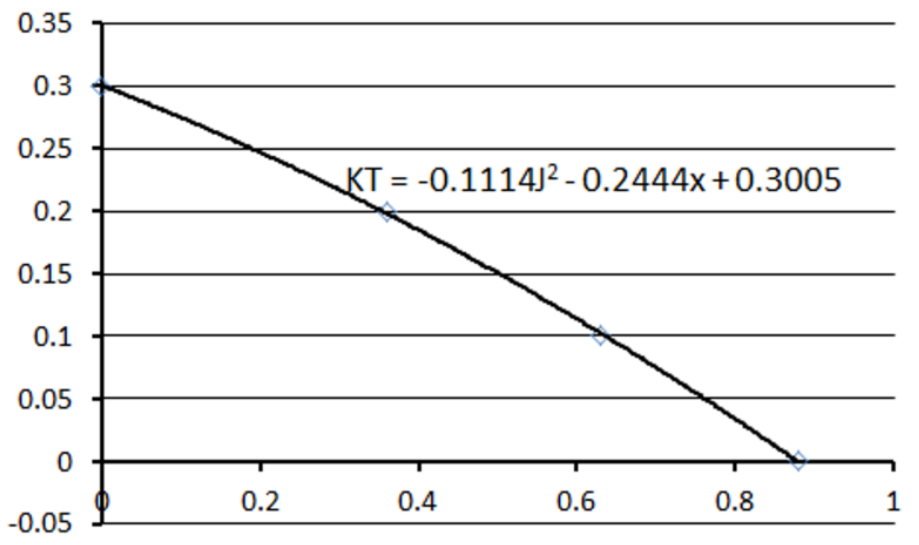

Figure 7: KT-J diagram
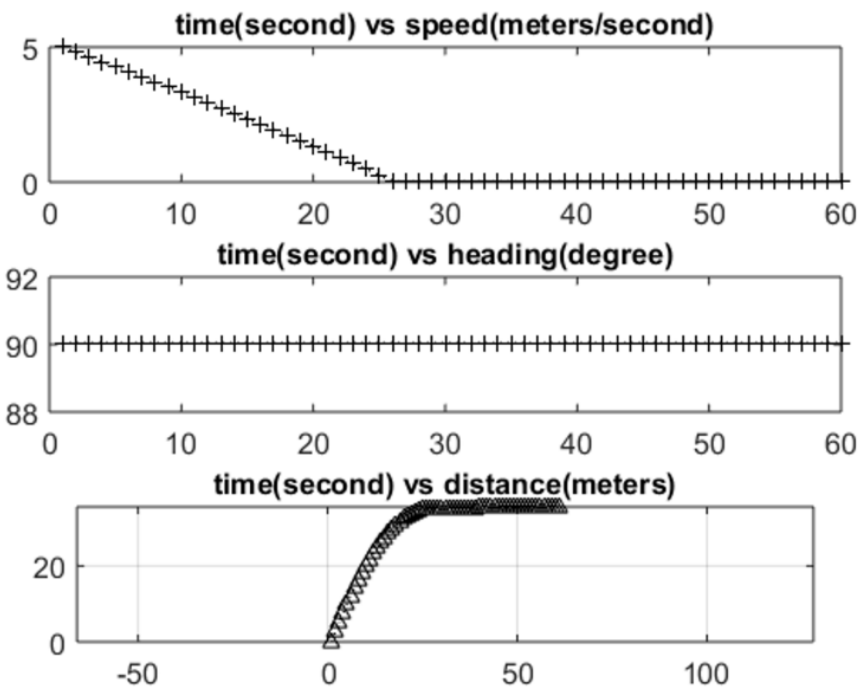

Figure 8: Stopping path based on MMG model 
The distance is about 4.5 times of the ship length which is 3 times longer than the stopping distance derived from AIS data.

\subsection{Safety Index of Vessels in the Research Area}

The traffic safety of the fishing vessel and passenger and merchant ship in the voyaging lane of the research area is analyzed based on AIS data derived from the website of marine traffic. The trajectory of the fishing vessel derived from the Android-based AIS is selected and the safety index of ES, Environment Stress is calculated. The data of traffic in the research area is shown in Table 3. The ES of the small fishing vessel and passenger ship in the selected position as shown in Figs. 9 and 10, respectively. The results of ES calculation are presented in Table 4.

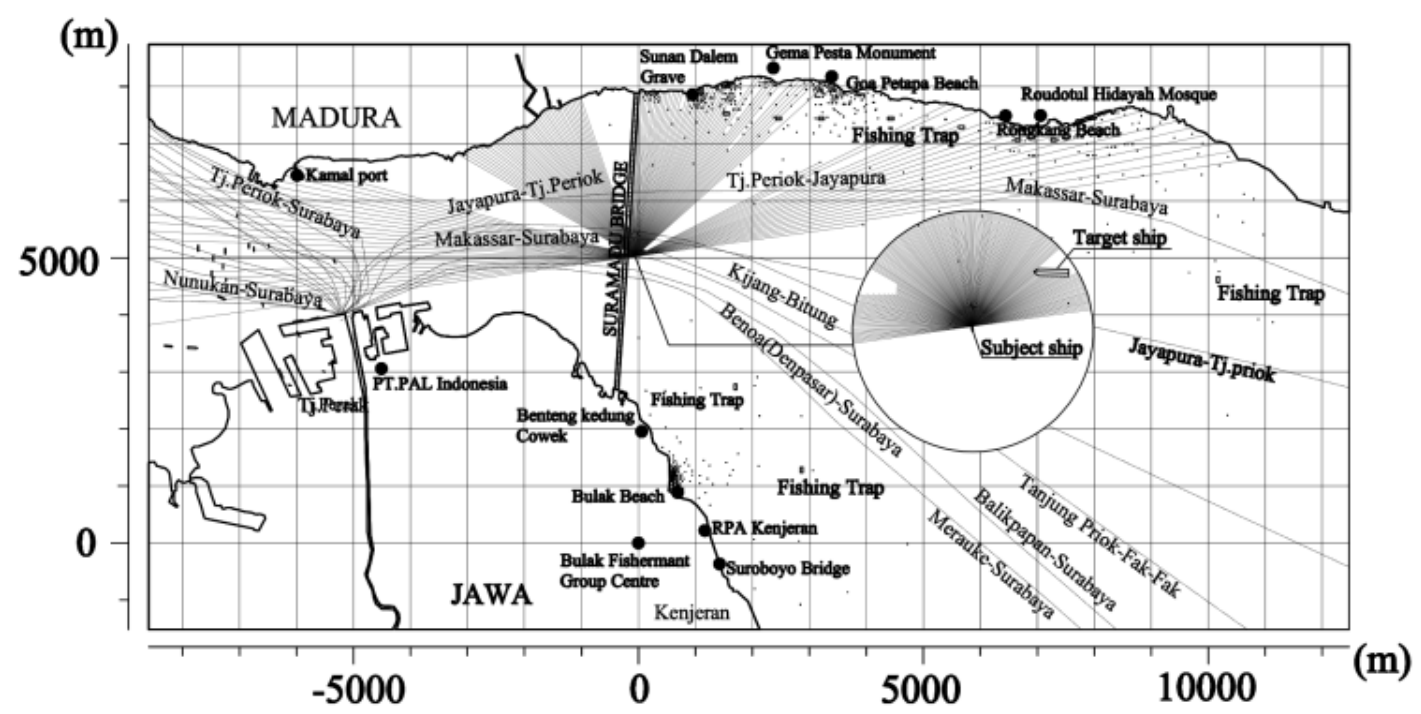

Figure 9: The ES of Fishing Vessel

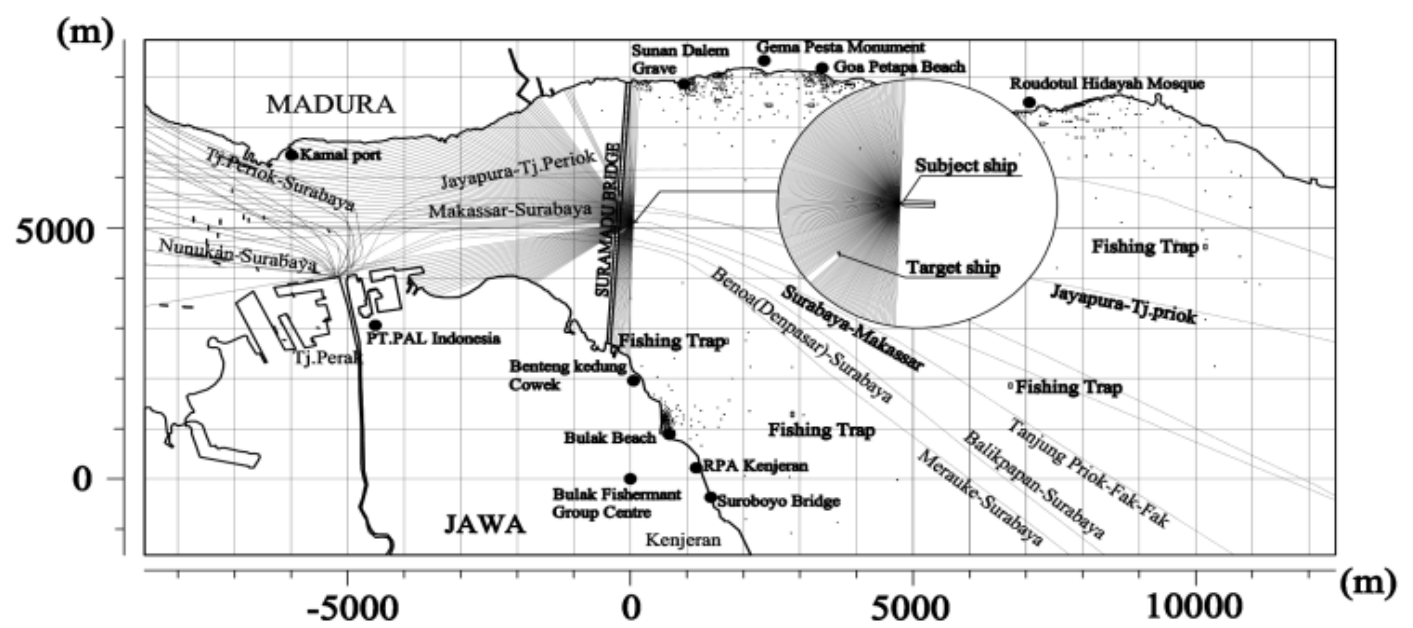

Figure 10: The ES of Passenger Ship 
Table 3: AIS Data from Https://www.marinetraffic.com/

\begin{tabular}{|c|l|c|}
\hline No. & \multicolumn{1}{|c|}{ Description } & Quantity \\
\hline 1 & Number of passege per day & 7 \\
\hline 2 & Average ship length (m) & 60.77 \\
\hline 3 & Average ship speed (knots) & 7.61 \\
\hline
\end{tabular}

Table 4: Environment Stress of Vessels

\begin{tabular}{|l|c|c|c|}
\hline \multirow{2}{*}{ The ES Safety Index } & \multicolumn{3}{|c|}{ Speed } \\
\cline { 2 - 4 } & 3 knots & 5 knots & 7 knots \\
\hline Small Fishing Vessel & 861 & 970 & 998 \\
\hline Passenger Ship & 1000 & 1000 & 1000 \\
\hline
\end{tabular}

The navigator difficulties in steering the pasenger ship in the area enters a catastrophic condition (ES is more than 900). The stress of small fishing vessels is in the critical condition (ES is more than 750 and less than 900) at the speed of 3 knots. The marginal condition will occur if ES is more than 500 and less than 750. The ES will be in a negligible condition if ES is less than 500.

The study has achieved one goal, the implementation of Android-based AIS as an effort to get AIS data covering all vessels in the area. The application of using the Android-based AIS data on the calculation of safety indices have been implemented.

However, the other goal, the effort to develop MMG model for the small coastal fishing vessels has not yet met with the same value derived from the Android-based AIS data. The estimate stopping distance of the MMG model is $4.5 \mathrm{~L}$ but the distance derived from the Android-based AIS is $1.5 \mathrm{~L}$.

\section{Conclusions}

According to the results of the study, the conclusions are as bellows:

1. The AIS data obtained from the Android-based system has a good quality on the course over ground, speed over ground and vessel heading. The data have been utilized to analyze the safety of navigation in the research area.

2. The traditional fishermen have gained information about their position, maximum safe speed in the danger area, and the safety index. The research found that the stopping distance of the small coastal fishing vessels is $1.5 \mathrm{~L}$ which is derived from the Android-based AIS data. The small fishing vessels should voyage at the maximum speed of 1.9 knots in a danger area, the crossing position of the voyaging lane. The vessels are still in a catastrophic condition if the speed is 3 knots.

3. The MMG model for the small coastal fishing vessel has been developed but it needs more investigation on the parameter of the model due to the high deviation of the estimated stopping distance of $4.5 \mathrm{~L}$ if it is compared to the Android-based AIS data. The stopping distance of $1.5 \mathrm{~L}$ derived from the Android-based AIS data also need to be investigated by using more experimental data. 


\section{Acknowledgment}

The authors would like to acknowledge to Politeknik Perkapalan Negeri Surabaya and Ministry of Research, Technology, and Higher Education for providing the research fund. The research is supported by the contract of applied research scheme, number: 220.14/PL19.P3M/PL/2017.

\section{References}

[1] http://globalfishingwatch.org/indonesia-vms-joint-statement/

[2] J. Montewka, P. Kujala, and J. Ylitalo, "The Quantitative Assessment of Marine Traffic Safety in the Gulf of Finland, on the Basis of AIS Data, " Scientific Journals of Maritime University of Szczecin, 2009, 18(90), 105-115

[3] A.A. Masroeri, K.B. Artana, T. Pitana, and D.D. Putranta, "A Review on Some Research Issues on AIS to Improve the Ship Safety Operation at Sea," 2012, Journal of Maritime Researches, 2 (1), 11-23.

[4] I.P.S. Asmara, E. Kobayashi, K.B. Artana, A.A. Masroeri, and N. Wakabayashi, "Simulation-Based Estimation of Collision Risk During Ship Maneuvering in Two-Lane Canal Using Mathematical Maneuvering Group Model and Automatic Identification System Data," In: ASME 2014 33rd International Conference on Ocean, Offshore and Arctic Engineering, Volume 4A: Structures, Safety and Reliability, Paper No. OMAE2014-23768, 2014, pp. V04AT02A055; 9 pages, DOI: 10.1115/OMAE2014-23768.

[5] Y. Yoshimura, and Y. Masumoto, "Hydrodynamic Database and Maneuvering Prediction Method with Medium High-Speed Merchant Ships and Fishing Vessels, " International MARSIM Conference, Singapore 2012, pp. 1-9.

[6] H. Yasukawa, Y. Yoshimura, "Introduction of MMG standard method for ship maneuvering predictions," Journal of Marine Science and Technology, DOI 10.1007/s00773-014-0293-y, 2014.

[7] T. Fujiwara, M. Ueno, and T. Nimura, "An Estimation Method of Wind Forces and Moments Acting on Ships," Mini Symposium on Prediction of Ship Maneuvering Performance, pp. 83-92, 2001.

[8] K. Inoue, M. Kawase, “Innovative Probabilistic Prediction of Accident Occurrence," International Journal on Marine Navigation and Safety of Sea transportation, vol. 1(1), pp. 19-22, 2007.

[9] K. Inoue, K. Masuda, W. Sera, "Guidelines to Assess the Safety of Marine Traffic-I. Evaluation of Ship-handling Difficulty based on the Environment Stress Model," The Journal of Japan Institute of Navigation, vol. 98, pp. 225233, 1997 (in Japanese).

[10]https://ideabagoes.files.wordpress.com/2010/12/rancangan-propeller-optimum-kapal-ikan.pdf 